\title{
PREPARATION OF NANO-POROUS ALUMINUM PHOSPHATE USING UREA AND HEXAMETHYLENETETRAMINE
}

\author{
HIROAKI ONODA ${ }^{1,2}$, SAYAKO UKITA ${ }^{2}$, AKI HAYASHI ${ }^{3}$, \\ ATSUSHI TAKENAKA ${ }^{4}$, KAZUO KOJIMA ${ }^{2}$
}

1; Department of Materials Science and Engineering, Faculty of Engineering, Kyoto University, Yoshida-Honmachi, Sakyo-ku, Kyoto 606-8501, Japan 2; Department of Applied Chemistry, Faculty of Science and Engineering, Ritsumeikan University, 1-1-1, Nojihigashi, Kusatsu, Shiga 525-8577, Japan 3; Kobe Pharmaceutical University, 4-19-1, Motoyamakita, Higashinada, Kobe, 658-8558, Japan

4; Department of Materials Science, Yonago National College of Technology, 4448, Hikona-cho, Yonago, Tottori 683-8502, Japan

\begin{abstract}
Aluminum orthophosphate was prepared from aluminum nitrate solution and phosphoric acid solution in the molar ratio of $A \mathrm{l} / \mathrm{P}=1 / 1$. Urea and hexamethylenetetramine were added in this preparation process. The thermal behavior of the obtained phosphates was analyzed by differential thermal analyses, X-ray diffraction, and Fourier transform infrared spectroscopy. Furthermore, these materials and their thermal products were estimated by scanning electron micrograph and particle size distribution. Specific surface areas and pore size distribution of phosphates were calculated from the amount of nitrogen gas adsorbed at the temperature of liquid nitrogen by BET and DH methods. The acidic property was estimated from the adsorption of trimethylamine gas.
\end{abstract}

\section{INTRODUCTION}

Phosphates have been used for ceramic materials, catalysts, adsorbent, fluorescent materials, dielectric substances, metal surface treatment, manure, detergent, food additives, fuel cells, pigments, etc. It is well known that aluminum phosphate works in various reactions as acidic catalysts. The catalytic and adsorptive properties of materials were influenced from specific surface areal3). To improve the functional properties, nano-porous phosphate which has large specific surface area is tried to be prepared. The addition of urea and so on had some possibility to obtain large specific surface area ${ }^{4,5}$ ).

In this work, aluminum orthophosphates containing urea and hexamethylenetetramine were prepared from aluminum nitrate solution, phosphoric 
acid solution, urea and hexamethylenetetramine. The obtained precipitation was estimated by differential thermal analysis, X-ray diffraction, and Fourier transform infrared spectroscopy. Furthermore, specific surface area, pore size distribution, SEM images, particle size distribution, and adsorption of trimethylamine were measured to clarify the properties of this phosphate.

\section{EXPERIMENTAL}

$0.1 \mathrm{~mol} / 1$ of aluminum nitrate solution was mixed to $0.1 \mathrm{~mol} / \mathrm{l}$ of phosphoric acid solution in the molar ratio of $\mathrm{Al} / \mathrm{P}=1 / 1$. Urea and hexamethylenetetramine were added in this mixed solution to the prescribed concentration. Then, the solution was prepared to $\mathrm{pH} 7$ with ammonia solution. The precipitation was filtered off and dried.

The thermal behavior of these materials was analyzed by differential thermal analyses (DTA), X-ray diffraction (XRD), and Fourier transform infrared spectroscopy (FT-IR). DTA curves were measured with a Rigaku Denki DTA50. Thermal analyses were carried out at $10^{\circ} \mathrm{C} / \mathrm{min}$. XRD patterns were recorded on a Rigaku Denki RINT 2000M X-Ray diffractometer using monochromated CuK $\alpha$ radiation. The IR spectra were recorded on a Shimadzu FT-IR spectrometer FTIR8600 with a $\mathrm{KBr}$ disk method.

Furthermore, these materials and their thermal products were estimated by scanning electron micrograph and particle size distribution. SEM images were observed using Hitachi F-4300. Particle size distribution was measured with laser diffraction/scattering particle size distribution HORIBA LA-910. Specific surface areas and pore size distribution of phosphates were calculated from the amount of nitrogen gas adsorbed at the temperature of liquid nitrogen by BET and DH methods with Belsorp mini from BEL JAPAN, INC. The acidic property of phosphates was estimated from the adsorption of trimethylamine gas at room temperature. The $0.01 \mathrm{~g}$ of samples was placed in a gas bag $\left(3000 \mathrm{~cm}^{3}\right)$ of polyethylene, which was then filled with trimethylamine gas $(16.6 \mathrm{ppm})$. The concentration of trimethylamine gas was determined with a Kitagawa gas detector after the standing for several minutes.

\section{RESULTS AND DISCUSSION}

Figure 1 shows DTA curves of samples prepared in various conditions. All samples had an endothermic peak below $100^{\circ} \mathrm{C}$ and samples prepared with urea indicated an endothermic peak at about $190^{\circ} \mathrm{C}$ in DTA curves. The broad endothermic peak at about $200^{\circ} \mathrm{C}$ was observed in DTA curve of sample prepared with hexamethylenetetramine (Fig. 1(e)).

All samples and their thermal products below $600^{\circ} \mathrm{C}$ were amorphous phase in XRD analyses. Figure 2 shows IR spectra of samples prepared in various 


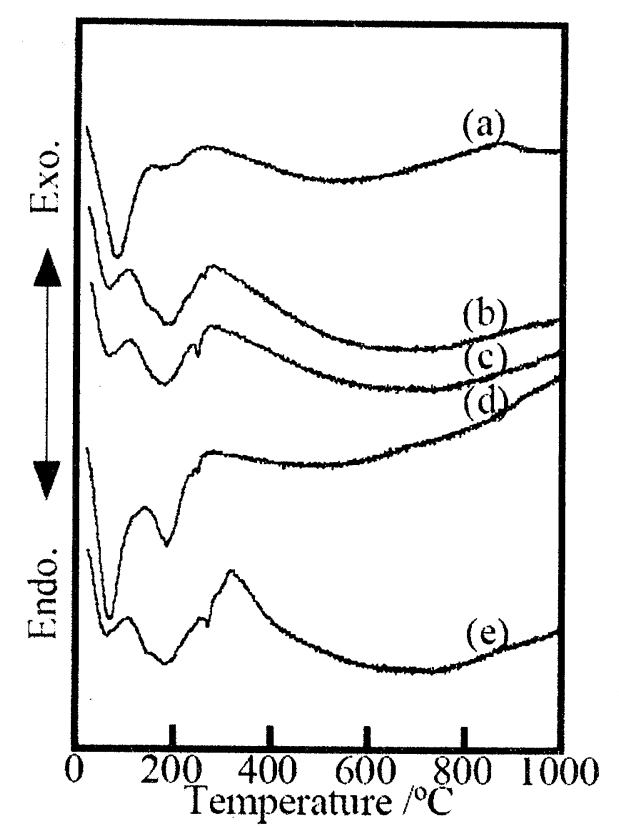

FIGURE 1. DTA curves of aluminum phosphates prepared in various conditions, (a) no additive, (b) urea, $0.5 \mathrm{~mol} / \mathrm{l}$, (c) urea, $1.0 \mathrm{~mol} / \mathrm{l}$, (d) urea, $1.5 \mathrm{~mol} / \mathrm{l}$, and (e) hexamethylenetetramine, $0.5 \mathrm{~mol} / \mathrm{l}$.

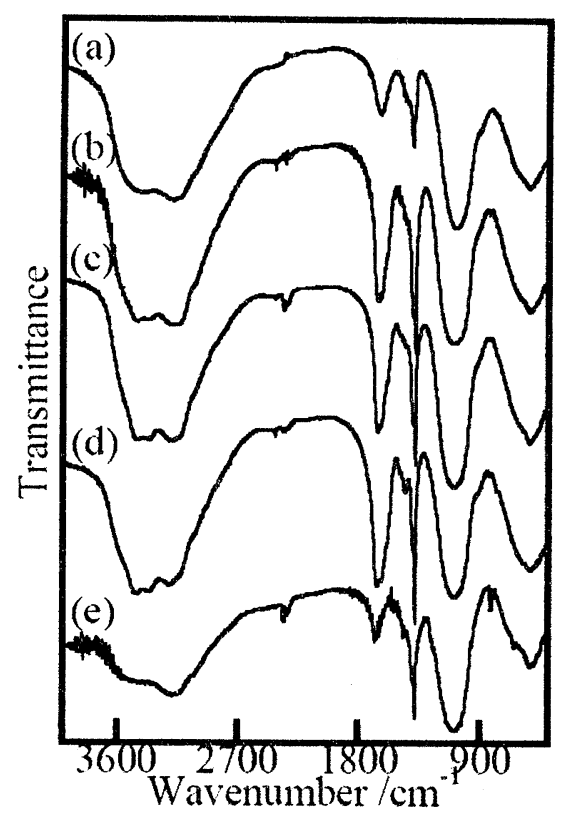

FIGURE 2. IR spectra of aluminum phosphates prepared in various conditions, (a) no additive, (b) urea, $0.5 \mathrm{~mol} / \mathrm{l}$, (c) urea, $1.0 \mathrm{~mol} / \mathrm{l}$, (d) urea, $1.5 \mathrm{~mol} / \mathrm{l}$, and (e) hexamethylenetetramine, $0.5 \mathrm{~mol} / \mathrm{l}$.

conditions. Samples prepared with urea had the similar IR spectrum in spite of the concentration of urea. The kind of the additives had much influence on the condition of the precipitation than the concentration of the additives. The absorption peak at about $1380 \mathrm{~cm}^{-1}$ in IR spectra of all samples disappeared by heating to $200^{\circ} \mathrm{C}$. This peak was considered to be due to ammonia and nitrate ions. These components volatilized below $200^{\circ} \mathrm{C}$. The heat treatment made the intensity of the absorption peaks at about 1670 and $3150-3600 \mathrm{~cm}^{-1}$. The materials had some condition of $\mathrm{O}-\mathrm{H}$ bonding because the broad absorption peak at $3150-3600 \mathrm{~cm}^{-1}$.

The endothermic peak below $100^{\circ} \mathrm{C}$ was due to the volatilization of water, ammonia, and nitrogen oxide. Urea and hexamethylenetetramine were considered to be decomposed to $\mathrm{NH} 3$ and $\mathrm{CO} 2$ at about $190^{\circ} \mathrm{C}$ from DTA curves.

Table 1 indicates specific surface area of samples prepared in various conditions and their thermal products. Samples heated at $100^{\circ} \mathrm{C}$ had smaller specific surface area than samples heated over $200^{\circ} \mathrm{C}$. The volatilization of urea, hexamethylenetetramine, a small amount of ammonium nitrate, and so on made specific surface area of materials increase. Samples prepared with urea and hexamethylenetetramine had large specific surface area than samples prepared without an additive. The concentration of urea had less influence on the specific surface area. 
Table 1 Specific surface area of various aluminum phosphates

\begin{tabular}{cccccc}
\hline Additive & $\begin{array}{c}\text { Concentration } \\
\text { /mol-g-1 }\end{array}$ & 100 & 200 & 400 & 600 \\
\hline non & 0 & 95.38 & 132.54 & 123.71 & 130.01 \\
urea & 0.5 & 126.23 & & 150.42 & \\
urea & 1.0 & 62.40 & & 130.47 & \\
urea & 1.5 & 82.84 & 149.85 & 153.18 & 142.21 \\
hmt & 0.5 & 116.74 & & 180.69 & \\
\hline
\end{tabular}

hmt; hexamethylenetetramine.

Figure 3 shows pore size distribution of samples heated at $100^{\circ} \mathrm{C}$. Sample prepared without an additive had a large amount of pore which was a radius of about $25 \mathrm{~nm}$. On the other hand, materials prepared with urea and hexamethylenetetramine had smaller pores. The pore size distribution of materials heated at $400^{\circ} \mathrm{C}$ is shown in Figure 4 . The small pore which was below pore radius of $10 \mathrm{~nm}$ increased from the decomposition and volatilization of urea and hexamethylenetetramine. This increase of small pore caused the improvement of specific surface area of phosphate.

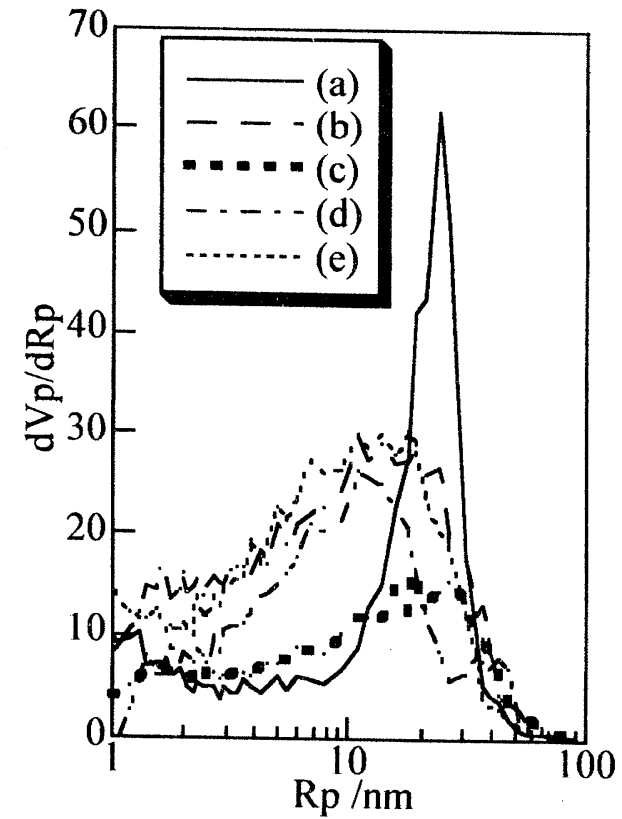

FIGURE 3. Pore size distribution of samples prepared in various conditions and heated at $100^{\circ} \mathrm{C}$, (a) no additive, (b) urea, $0.5 \mathrm{~mol} / \mathrm{l}$, (c) urea, $1.0 \mathrm{~mol} / \mathrm{l}$, (d) urea, $1.5 \mathrm{~mol} / \mathrm{l}$, and (e) hexamethylenetetramine, $0.5 \mathrm{~mol} / \mathrm{l}$.

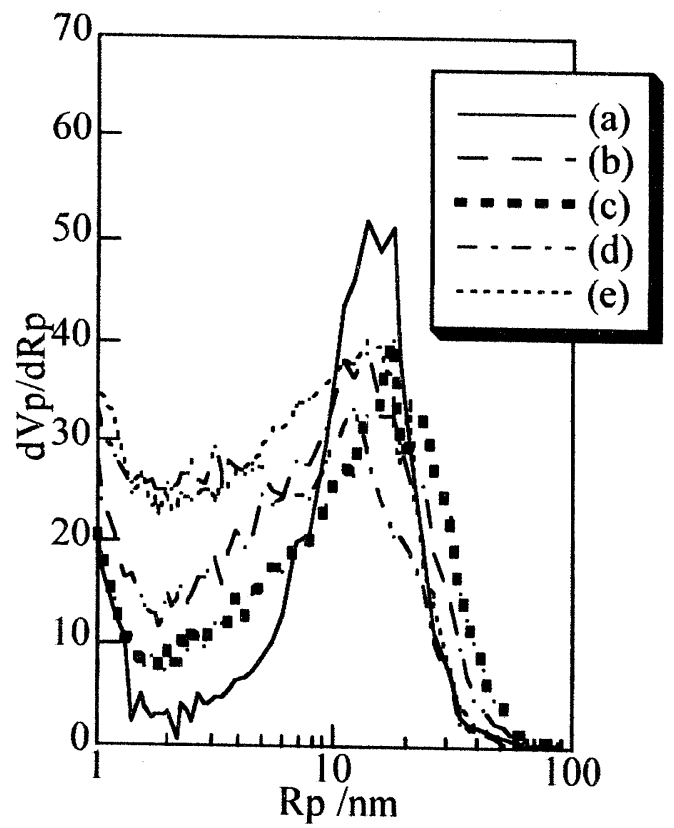

FIGURE 4. Pore size distribution of samples prepared in various conditions and heated at $400^{\circ} \mathrm{C}$, (a) no additive, (b) urea, $0.5 \mathrm{~mol} / \mathrm{l}$, (c) urea, $1.0 \mathrm{~mol} / \mathrm{l}$, (d) urea, $1.5 \mathrm{~mol} / \mathrm{l}$, and (e) hexamethylenetetramine, $0.5 \mathrm{~mol} / \mathrm{l}$. 
Table 2 Median and average particle sizes of various aluminum phosphates heated at $400^{\circ} \mathrm{C}$

\begin{tabular}{cccc}
\hline Additive & $\begin{array}{c}\text { Concentration } \\
/ \text { mol•g- }^{-1}\end{array}$ & $\begin{array}{c}\text { Median particle size } \\
/ \mu \mathrm{m}\end{array}$ & $\begin{array}{c}\text { Average particle size } \\
/ \mu \mathrm{m}\end{array}$ \\
\hline non & 0 & 102.0 & 142.0 \\
urea & 0.5 & 75.1 & 146.1 \\
urea & 1.0 & 45.6 & 48.6 \\
urea & 1.5 & 135.8 & 211.4 \\
hmt & 0.5 & 50.9 & 58.5 \\
\hline
\end{tabular}

hmt; hexamethylenetetramine.

From SEM images, all aluminum phosphates did not have a specified shape. Table 2 indicates the median and average particle sizes calculated from the particle size distribution of samples heated at $400^{\circ} \mathrm{C}$. The average particle size of all samples was larger than the median particle size. All samples consisted of major part of small particles and minor part of much large particles. The addition of urea and hexamethylenetetramine had less influence on particle shape and size.

Figure 5 shows adsorption of trimethylamine on aluminum phosphates heated at $100^{\circ} \mathrm{C}$. The adsorption ratio of all phosphates grew to 3 minutes and then kept their balance. The phosphates prepared with urea and hexamethylenetetramine indicated lower adsorption ratio than that prepared without. Urea and hexamethylenetetramine were considered to decline acidic properties of aluminum phosphate. Samples heated at $400^{\circ} \mathrm{C}$ had same tendency with those at $100^{\circ} \mathrm{C}$. A small amount of urea and hexamethylenetetramine still remained on surface of aluminum phosphate. The longer heating time was needed to remove urea and haxamethylenetetramine.

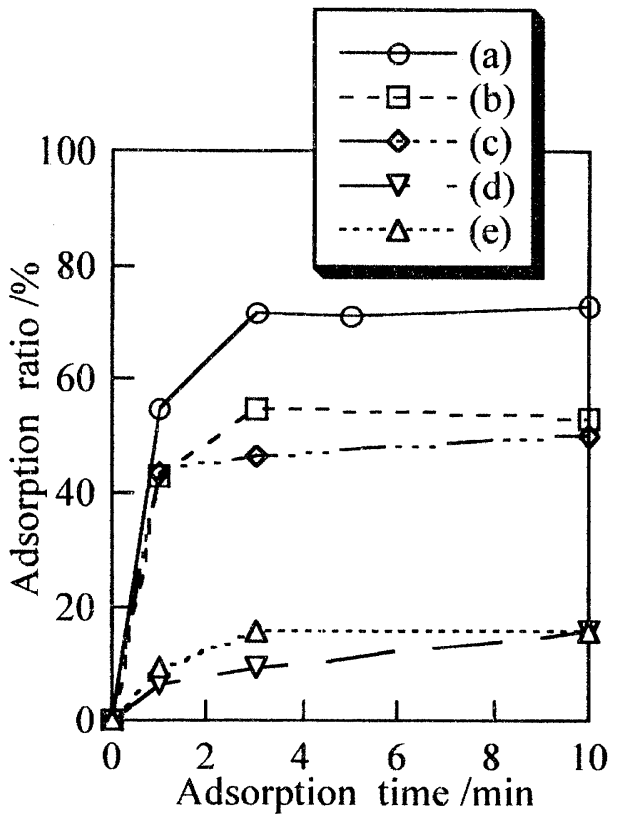

FIGURE 5. Adsorption of trimethylamine on aluminum phosphates prepared in various conditions, (a) no additive, (b) urea, $0.5 \mathrm{~mol} / \mathrm{l}$, (c) urea, $1.0 \mathrm{~mol} / \mathrm{l}$, (d) urea, $1.5 \mathrm{~mol} / \mathrm{l}$, and (e) hexamethylenetetramine, $0.5 \mathrm{~mol} / \mathrm{l}$. 


\section{CONCLUSION}

The porous aluminum phosphate was obtained by the addition of urea and hexamethylenetetramine to the preparation with water, and then heating. This materials had smaller nano-pores than pore radius of $10 \mathrm{~nm}$. The addition of urea and hexamethylenetetramine had less influence on particle shape and size. The remained urea and hexamethylenetetramine in heated materials had the possibility to control the acidic properties on surface of aluminum phosphate.

\section{REFERENCES}

1) H. Onoda, H. Nariai, H. Maki and I. Motooka, Phosphorus Res. Bull., 12, 139$146(2001)$.

2) H. Onoda, H. Nariai, A. Moriwaki, H. Maki and I. Motooka, J. Mater. Chem., 12(6), 1754-1260 (2002).

3) H. Onoda, H. Nariai, H. Maki and I. Motooka, Phosphorus Res. Bull., 9, 69-74 (1999).

4) K. Kandori, N. Ikegami, A. Yasukawa and T. Ishikawa, J. Coll. Interf. Sci., 182, 425-430 (1996).

5) H. Onoda, H. Nariai, H. Maki and I. Motooka, J. Mater. Syn._Proc., 10(3), 121-126 (2002). 